\title{
Comparison of Characteristics and Survival Rates of Resectable Pancreatic Ductal Adenocarcinoma according to Tumor Location
}

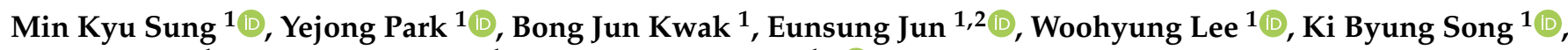 \\ Jae Hoon Lee ${ }^{1}$, Dae Wook Hwang ${ }^{1}$ and Song Cheol Kim ${ }^{1, * \mathbb{D}}$ \\ 1 Division of Hepato-Biliary and Pancreatic Surgery, Department of Surgery, \\ University of Ulsan College of Medicine and Asan Medical Center, 88, Olympic-Ro 43-Gil, Songpa-Gu, \\ Seoul 05505, Korea; skystar8608@naver.com (M.K.S.); blackpig856@gmail.com (Y.P.); \\ bjkwak0827@gmail.com (B.J.K.); eunsungjun@amc.seoul.kr (E.J.); ywhnet@gmail.com (W.L.); \\ mtsong21c@naver.com (K.B.S.); gooddr23@naver.com (J.H.L.); drdwhwang@gmail.com (D.W.H.) \\ 2 Convergence Medicine, University of Ulsan College of Medicine, Seoul 05505, Korea \\ * Correspondence: drksc@amc.seoul.kr; Tel.: +82-2-3010-3936; Fax: +82-2-474-9027
}

check for updates

Citation: Sung, M.K.; Park, Y.; Kwak, B.J.; Jun, E.; Lee, W.; Song, K.B.; Lee, J.H.; Hwang, D.W.; Kim, S.C.

Comparison of Characteristics and Survival Rates of Resectable Pancreatic Ductal Adenocarcinoma according to Tumor Location. Biomedicines 2021, 9, 1706. https:// doi.org/10.3390/biomedicines9111706

Academic Editor: David R. Wallace

Received: 18 October 2021

Accepted: 14 November 2021

Published: 17 November 2021

Publisher's Note: MDPI stays neutral with regard to jurisdictional claims in published maps and institutional affiliations.

Copyright: (c) 2021 by the authors. Licensee MDPI, Basel, Switzerland. This article is an open access article distributed under the terms and conditions of the Creative Commons Attribution (CC BY) license (https:// creativecommons.org/licenses/by/ $4.0 /)$.

\begin{abstract}
The impact of tumor location on patient survival in pancreatic ductal adenocarcinoma (PDAC) remains controversial. This study investigated the association between primary tumor location and survival rates for resectable PDAC. Additionally, we assessed if this association remains consistent across categories of the Tumor-Node-Metastasis staging system. We analyzed 2471 patients who underwent surgical resection between 2000 and 2018 at a single center. Subgroup analysis was performed according to the Tumor-Node-Metastasis staging system. Among the group, $67.9 \%$ (1677 patients) had pancreatic head cancer (PHC) and 32.1\% (794 patients) had pancreatic body/tail cancer (PBTC). Patients with PHC had worse overall survival and worse disease-free survival than those with PBTC. Patients with PHC had worse survival in stage IB and stage IIB than those with PBTC. No significant difference was observed for stages IA, IIA, and III. Multivariate analysis showed that elevated CA 19-9, mGPS, a longer hospital stay, complication, accompanying vein resection, larger tumor size, worse differentiation, higher TNM stage (stage IIB, III, IV), presence of LVI, and positive resection margin were risk factors for poor survival after resection. In resectable PDAC, patients with PHC had worse overall and disease-free survival than those with PBTC. However, tumor location was not an independent prognostic factor for PDAC.
\end{abstract}

Keywords: pancreatic ductal adenocarcinoma; location; head; body/tail; survival

\section{Introduction}

Pancreatic ductal adenocarcinoma (PDAC) is the leading cause of cancer-related deaths worldwide, and its annual incidence and prevalence are steadily increasing [1,2]. Owing to improvements in diagnostic modalities and frequent health screening, early diagnosis of PDAC has become possible, which has increased overall survival rates [3]. Nevertheless, the mortality rate for PDAC remains exceptionally high due to its rapid progression and quick recurrence [3]. Therefore, it is important to understand factors that can influence PDAC prognosis.

PDAC is categorized into pancreatic head cancer (PHC) and pancreatic body and tail cancer (PBTC) based on anatomical location and embryologic origin [3]. Since PHC and PBTC have different clinical symptoms and treatment regimens, a significant difference between their survival rates has been previously reported [3]. There were several studies that have suggested the anatomical location of the PDAC is a prognostic factor for survival [4-11]. However, recently several studies suggested the opposite results [12-15]. In general, survival rates and prognosis are worse in patients with PBTC compared with those with PHC due to late diagnosis in the absence of noticeable symptoms such as 
obstructive jaundice $[4,9,13,16-19]$. However, few studies have shown similar postoperative oncological outcomes for PHC and PBTC despite larger tumor sizes among PBTC patients [5,7]. In contrast, some studies have shown the survival for PHC was worse than that for PBTC, which included early stage resectable PDAC [20,21].

Therefore, the impact of tumor location on patient survival for PDAC has been controversial, and the association seems to vary according to tumor characteristics such as size and stage. In this study, we investigated the association between primary tumor location and overall survival rates among resectable PDAC patients. Furthermore, we investigated whether this association remains consistent across categories of the Tumor-Node-Metastasis (TNM) staging system. Moreover, we determined the prognostic factors for overall survival for both PHC and PBTC patients.

\section{Materials and Methods}

\subsection{Study Participants}

All PDAC patients who underwent surgical resection between January 2000 and December 2018 at a single center were consecutively enrolled in this retrospective cohort study. Patients who underwent any operations for palliative measures (i.e., bypass surgery, open and biopsy) were excluded. Only patients diagnosed with PDAC were enrolled in this study. The number of patients diagnosed with other histological carcinomas (such as adenosquamous carcinoma, signet ring cell carcinoma, colloid carcinoma, and so on) was very small and they generally had a poorer prognosis than PDAC. Therefore, we excluded those with other histological diagnoses. Among the 2730 PDAC patients, we excluded 26 patients because their tumor locations could not be classified as either PHC or PBTC due to large tumor size. We excluded an additional 233 patients who underwent neoadjuvant chemotherapy due to variations in their chemotherapeutic regimen. For resectable pancreatic cancer, surgery is performed first, followed by adjuvant chemotherapy. However, for borderline resectable pancreatic cancer, neoadjuvant chemotherapy is recommended before surgery. Further, in these cases, some patients may have a higher T stage compared to others. If they are included in the resectable pancreatic cancer group, there may be a bias in the survival rate analysis. Therefore, these patients were excluded from this study. Ultimately, 2471 patients were included in the final analysis. Among the 2471 PDAC patients, 1677 (67.9\%) patients had PHC, and 794 (32.1\%) patients had PBTC.

\subsection{Preoperative Evaluation and Surgical Procedure}

Participants underwent preoperative, pancreas protocol computed tomography (CT) and magnetic resonance cholangiopancreatography (MRCP) for the initial evaluation of cancer stage and resectability. If distant metastasis was suspected, participants underwent 18F-fluorodeoxyglucose positron emission tomography (FDG-PET). We performed upfront surgery on patients who met the criteria for resectable tumors. If pancreatic cancer was confined to the pancreatic parenchyma, a standard procedure based on anatomical location was performed (pancreaticoduodenectomy for PHC and distal pancreatectomy for PBTC). If the resection margin was positive from the frozen biopsy, we performed a total pancreatectomy for complete R0 resection. Vascular resection was performed when PDAC had invaded the adjacent vessels, and organ-combined resection was performed when PDAC had invaded adjacent organs. Since 2006, we have performed laparoscopic surgery in cases of benign or suspected early PDAC. There have been 24 cases of robot-assisted surgery since 2016.

\subsection{Data Collection}

Patient data were collected from their electronic medical records. The data included demographic factors, namely age, sex, and body mass index (BMI), and American Society of Anesthesiologists (ASA) scores as well as preoperative carbohydrate antigen (CA 19-9), carcinoembryonic antigen (CEA), $\mathrm{C}$ reactive protein (CRP), and albumin levels to calculate the modified Glasgow prognostic score (mGPS) [22,23]. Length of hospital stay was 
categorized as $\leq 15$ days and $>15$ days. We evaluated the presence of postoperative pancreatic fistula (POPF) and its complications. POPF was defined according to the 2016 International Study Group of Pancreas Surgery, and surgery-related complications were graded according to the Clavien-Dindo system [24,25]. We further categorized the participants according to adjuvant chemotherapy and chemoradiation therapy status. Tumors were categorized according to location as either head or body/tail cancer, and the operation method was categorized as either open or laparoscopic/robotic surgery. We also evaluated the status of the vein resection, artery resection and organ combined resection. Pathologic characteristics such as tumor size, differentiation, TNM staging, lymphovascular invasion (LVI), perineural invasion (PNI), and resection margin were evaluated. The degree of tumor differentiation was described according to the World Health Organization's nomenclature, and TNM staging was classified based on the American Joint Committee on Cancer (AJCC) cancer staging system (8th edition) [26].

\subsection{Outcome}

The primary outcome was the overall survival (OS) rates for both the PHC and PBTC groups. Patients were followed up from the date of operation to the date of last outpatient clinic visit or death, whichever came first. The secondary outcome was disease-free survival (DFS) rates for both groups. DFS was defined as the time to relapse or all-cause death, whichever came first. Recurrence was defined as recurrence noted from a follow-up CT scan regardless of cancer-related symptoms. Of the 2471 patients, 1859 patients had an unambiguous date of death due to recurrence of PDAC after surgery. The exact date of death of 612 patients is unknown. Survival analysis was performed based on the date of the last outpatient visit. There were no deaths due to factors other than PDAC during this period.

\subsection{Statistical Analysis}

Descriptive analysis was performed for baseline patient characteristics. Categorical variables were presented as number and percentage, and continuous variables were presented as either mean (standard deviation) or median (interquartile range). The Chi-square test was used to compare categorical variables, and the Student's $t$-test was used to compare continuous variables. We plotted the Kaplan-Meier survival curves and performed a log-rank test to compare OS and DFS rates of the PHC and PBTC groups. To determine prognostic factors for survival, the Cox proportional hazard model was used to calculate the relative risk ratios (RRs) and $95 \%$ confidence intervals (CIs). Subgroup analysis was performed according to the TNM stage. A two-tailed $p<0.05$ was considered statistically significant, and all analyses were conducted using SPSS version 23.0 (IBM Corp., Armonk, NY, USA).

\section{Results}

\subsection{Comparison of Patient Characteristics in PHC and PBTC Group}

Tables 1 and 2 show the comparison of demographic, clinical, surgical, and pathological patient characteristics of the PHC and PBTC groups. Among the 2471 PDAC patients, 1677 (67.9\%) patients had PHC, and 794 (32.1\%) patients had PBTC. The prevalence of obesity was higher in PBTC patients. The PHC group had a higher proportion of patients with elevated CA 19-9, had higher mGPS scores, and had patients with longer length of hospital stay compared with the PBTC group. Clinically relevant POPF were more prevalent in PBTC patients. Complications above Grade B or C were higher in PBTC patients but there was no significance. They had undergone a greater number of laparoscopic and robot-assisted surgeries. The incidence of vein resection was higher in PHC patients, whereas the incidence of organ combined resection was higher in PBTC patients. PBTC patients also had larger tumor sizes and more distant metastasis, whereas PHC patients had more lymph node metastasis, LVI and PNI. 
Table 1. Comparison of demographic and clinical characteristics of all pancreatic ductal adenocarcinoma patients.

\begin{tabular}{|c|c|c|c|c|c|}
\hline & & Total & PHC Patients & PBTC Patients & \multirow{2}{*}{$p$-Value } \\
\hline & & N (\%) & N (\%) & N (\%) & \\
\hline \multirow[t]{2}{*}{ Age (year) } & $<65$ & $1424(57.6)$ & $981(58.5)$ & $443(55.8)$ & 0.204 \\
\hline & $\geq 65$ & 1047 (42.4) & $696(41.5)$ & $351(44.2)$ & \\
\hline \multirow[t]{2}{*}{ Sex } & Male & 1465 (59.3) & 675 (40.3) & 331 (41.7) & 0.407 \\
\hline & Female & 1006 (40.7) & 1002 (59.7) & $463(58.3)$ & \\
\hline \multirow[t]{2}{*}{$\mathrm{BMI}\left(\mathrm{kg} / \mathrm{m}^{2}\right)$} & $<25$ & 1912 (77.4) & 1335 (79.6) & 577 (72.7) & $<0.001$ \\
\hline & $\geq 25$ & $599(22.6)$ & $342(20.4)$ & 217 (27.3) & \\
\hline \multirow[t]{4}{*}{ ASA scores } & 1 & $54(2.6)$ & $33(2.5)$ & $21(2.9)$ & 0.090 \\
\hline & 2 & $1881(92.0)$ & 1245 (93.4) & $636(89.1)$ & \\
\hline & 3 & $108(5.3)$ & $54(4.1)$ & $54(7.6)$ & \\
\hline & 4 & $3(0.1)$ & $0(0.0)$ & $3(0.4)$ & \\
\hline \multirow[t]{2}{*}{ CA $19-9$} & Normal & $811(32.8)$ & $516(31.6)$ & $295(38.0)$ & 0.002 \\
\hline & Increased & 1599 (64.7) & $1118(68.4)$ & $481(62.0)$ & \\
\hline \multirow[t]{2}{*}{ CEA } & Normal & $1879(76.0)$ & 1263 (81.6) & $616(83.0)$ & 0.421 \\
\hline & Increased & $410(16.6)$ & $284(18.4)$ & $126(17.0)$ & \\
\hline \multirow[t]{3}{*}{ mGPS } & 0 & $2103(85.1)$ & 1386 (82.6) & 717 (90.3) & $<0.001$ \\
\hline & 1 & $128(5.2)$ & $94(5.6)$ & $34(4.3)$ & \\
\hline & 2 & $240(9.7)$ & $197(11.8)$ & $43(5.4)$ & \\
\hline \multirow{2}{*}{ Period } & 2000-2009 & $722(29.2)$ & $514(30.0)$ & $208(25.4)$ & 0.023 \\
\hline & 2010-2018 & $1749(70.8)$ & $1163(69.3)$ & $586(73.8)$ & \\
\hline \multirow[t]{2}{*}{ Length of hospital stay } & $\leq 15$ & $1287(52.1)$ & $767(45.7)$ & $520(65.5)$ & $<0.001$ \\
\hline & $>15$ & $1184(47.9)$ & $1481(54.3)$ & $274(34.5)$ & \\
\hline \multirow[t]{3}{*}{ POPF } & No & $2047(82.8)$ & $1484(88.5)$ & $563(70.9)$ & $<0.001$ \\
\hline & Grade A & $298(12.1)$ & $133(7.9)$ & $165(20.8)$ & \\
\hline & Grade B or C & $126(5.1)$ & $60(3.6)$ & $66(8.3)$ & \\
\hline \multirow[t]{3}{*}{ Complications } & No & $1595(64.7)$ & $1085(64.9)$ & $510(64.4)$ & 0.059 \\
\hline & Grade I-II & $683(27.7)$ & $475(28.4)$ & $208(26.3)$ & \\
\hline & Grade III-IV & $187(7.6)$ & $113(6.8)$ & $74(9.3)$ & \\
\hline \multirow{3}{*}{ Adjuvant therapy } & No & $707(29.2)$ & $492(29.9)$ & $215(27.5)$ & 0.289 \\
\hline & CTx & $1321(54.5)$ & $894(54.4)$ & $427(54.7)$ & \\
\hline & CCRTx & $397(16.3)$ & $258(15.7)$ & 139 (17.8) & \\
\hline
\end{tabular}

PHC, pancreatic head cancer; PBTC, pancreatic body/tail cancer; BMI, body mass index; ASA, American Society of Anesthesiologists; CA, carbohydrate antigen; CEA, carcinoembryonic antigen; mGPS, modified Glasgow prognostic score; POPF, postoperative pancreatic fistula; CTx, chemotherapy; CCRTx, concurrent chemoradiation therapy.

Table 2. Comparison of surgical and pathological characteristics of all pancreatic ductal adenocarcinoma patients.

\begin{tabular}{|c|c|c|c|c|c|}
\hline & & Total & PHC Patients & PBTC Patients & \multirow{2}{*}{$p$-Value } \\
\hline & & N (\%) & $\mathbf{N}(\%)$ & N (\%) & \\
\hline \multirow[t]{2}{*}{ Operation method } & Open & $2065(83.6)$ & $1602(95.5)$ & $463(58.3)$ & \multirow[t]{2}{*}{$<0.001$} \\
\hline & Lap/Robot & $406(16.4)$ & $75(4.5)$ & 331 (41.7) & \\
\hline \multirow[t]{2}{*}{ Vein resection } & No & $1828(74.0)$ & $1122(66.9)$ & 706 (88.9) & \multirow[t]{2}{*}{$<0.001$} \\
\hline & Yes & $643(26.0)$ & $555(33.1)$ & $88(11.1)$ & \\
\hline \multirow{2}{*}{ Artery resection } & No & $2344(94.9)$ & 1597 (95.2) & 747 (94.1) & \multirow[t]{2}{*}{0.227} \\
\hline & Yes & $127(5.1)$ & $80(4.8)$ & $47(5.9)$ & \\
\hline \multirow{2}{*}{$\begin{array}{l}\text { Organ combined } \\
\text { resection }\end{array}$} & No & $2347(95.0)$ & $1643(98.0)$ & 704 (88.7) & \multirow[t]{2}{*}{$<0.001$} \\
\hline & Yes & $124(5.0)$ & $34(2.0)$ & $90(11.3)$ & \\
\hline Tumor size $(\mathrm{cm})$ & Mean (sd) & $3.3(1.7)$ & $3.2(1.3)$ & $3.6(1.9)$ & $<0.001$ \\
\hline \multirow[t]{3}{*}{ Differentiation } & Well & $270(10.9)$ & 169 (10.3) & $101(13.0)$ & \multirow[t]{3}{*}{0.138} \\
\hline & Moderate & $1832(74.1)$ & 1257 (76.6) & 575 (74.2) & \\
\hline & Poor & 314 (12.7) & $215(13.1)$ & $99(12.8)$ & \\
\hline \multirow{4}{*}{ T stage } & $\mathrm{T} 1$ & $362(14.7)$ & $218(13.0)$ & $144(18.1)$ & \multirow[t]{4}{*}{$<0.001$} \\
\hline & $\mathrm{T} 2$ & $1603(64.9)$ & $1193(71.2)$ & $410(51.7)$ & \\
\hline & $\mathrm{T} 3$ & 467 (18.9) & $246(14.7)$ & $221(27.9)$ & \\
\hline & $\mathrm{T} 4$ & $37(1.5)$ & $19(1.1)$ & $18(2.3)$ & \\
\hline
\end{tabular}


Table 2. Cont.

\begin{tabular}{|c|c|c|c|c|c|}
\hline & & Total & PHC Patients & PBTC Patients & \multirow{2}{*}{$p$-Value } \\
\hline & & N (\%) & N (\%) & N (\%) & \\
\hline \multirow[t]{3}{*}{ N stage } & N0 & $996(40.3)$ & $642(38.5)$ & 354 (45.3) & 0.002 \\
\hline & N1 & $1072(43.4)$ & 745 (44.6) & $327(41.8)$ & \\
\hline & N2 & $383(15.5)$ & $282(16.9)$ & 101 (12.9) & \\
\hline \multirow[t]{2}{*}{ M stage } & M0 & $2368(95.8)$ & $1626(97.0)$ & 742 (93.5) & $<0.001$ \\
\hline & M1 & $103(4.2)$ & $51(3.0)$ & $52(6.5)$ & \\
\hline \multirow[t]{6}{*}{ Staging } & IA & $221(9.0)$ & $129(7.7)$ & 92 (11.8) & $<0.001$ \\
\hline & IB & $590(24.1)$ & $430(25.8)$ & $160(20.5)$ & \\
\hline & IIA & $146(6.0)$ & $72(4.3)$ & $74(9.5)$ & \\
\hline & IIB & 1017 (41.5) & $717(43.0)$ & $300(38.4)$ & \\
\hline & III & 372 (15.2) & $269(16.1)$ & 103 (13.2) & \\
\hline & IV & $103(4.2)$ & $51(3.1)$ & $52(6.6)$ & \\
\hline \multirow[t]{2}{*}{ LVI } & No & 1163 (47.1) & $718(42.8)$ & $445(56.0)$ & $<0.001$ \\
\hline & Yes & 1308 (52.9) & 959 (57.2) & $349(44.0)$ & \\
\hline \multirow[t]{2}{*}{ PNI } & No & 466 (18.9) & 271 (16.2) & 195 (24.6) & $<0.001$ \\
\hline & Yes & 2005 (81.1) & $1406(83.8)$ & $599(75.4)$ & \\
\hline \multirow[t]{2}{*}{$\mathrm{RM}$} & R0 & $1896(75.6)$ & $1284(76.6)$ & 585 (73.7) & 0.118 \\
\hline & $\mathrm{R} 1$ & $602(24.4)$ & $393(23.4)$ & 209 (26.3) & \\
\hline
\end{tabular}

Abbreviations: PHC, pancreatic head cancer; PBTC, pancreatic body/tail cancer; LVI, lymphovascular invasion; PNI, perineural invasion; RM, resection margin.

\subsection{Comparison of Survival Rates for PHC and PBTC Patients}

The median survival for the entire cohort was 27 months (range 0-227 months). Figure 1 shows the OS and DFS curves according to the location of PDAC. Both OS and DFS rates were lower among PHC patients compared with PBTC patients (median overall survival: 24 months vs. 34 months, $p=0.001$; median disease-free survival: 12 months vs. 18 months, $p=0.0012$ ). Stage III PDAC is defined by involvement of the celiac axis, superior mesenteric artery, and/or common hepatic artery, regardless of size, or as having four or more lymph node metastases. Therefore, it is a relatively advanced cancer compared to stage I/II PDAC. Patients were categorized accordingly, and their survival rates were compared (Figure 2). Both OS and DFS rates were lower among PHC patients compared with PBTC patients (overall survival: 24 months vs. 30 months, $p=0.002$; disease-free survival: 10 months vs. 13 months, $p=0.0019)$ with stage I/II PDAC. However, no significant difference was found between PHC patients and those with stage III PDAC (overall survival: $p=0.1$; disease-free survival: $p=0.099$ ). Figure 3 shows the comparison of survival rates of PHC and PBTC patients in the stage I/II group, without any significant difference. The survival rates were lower in PHC patients compared with PBTC patients in stage IB (30 months vs. 42 months, $p=0.011$ ) and stage IIB (19 months vs. 23 months, $p=0.048)$. No significant difference between the two groups was observed for stages IA and IIA.

\subsection{Potential Predictors for Overall Survival of PDAC Patients}

Table 3 shows the factors associated with the overall survival of PDAC patients. In multivariable analysis, the OS was worse in patients with elevated CA 19-9 levels, mGPS score 1, a longer hospital stay (>15 days), complication Grade I-II, accompanying vein resection, larger tumor size, worse differentiation, higher TNM stage (stage IIB, III, IV), presence of LVI, and positive resection margin. The OS was better in patients who had received adjuvant therapy, and patients who had undergone laparoscopic or robotic surgery. Tumor location was not associated with OS in the multivariate analysis.

Supplementary Tables S1 and S2 show the results for the subgroup analysis according to tumor location. For PHC, the overall survival rate was worse in patients with higher mGPS (score 1), a longer hospital stay (>15 days), complication Grade I-II, accompanying vein resection, larger tumor size, worse differentiation, higher TNM stage (stage IIB, III, IV), 
and the presence of LVI. The OS was better in patients who had received adjuvant therapy (Table S1). In PBTC patients, the overall survival rate was worse in patients with elevated CA 19-9 levels, a longer hospital stay ( $>15$ days), larger tumor size, worse differentiation, higher TNM stage (stage IIB, III, IV), presence of LVI and PNI, and positive resection margin. The overall survival was better in patients who had received adjuvant therapy and those who had undergone laparoscopic or robotic surgery (Table S2).
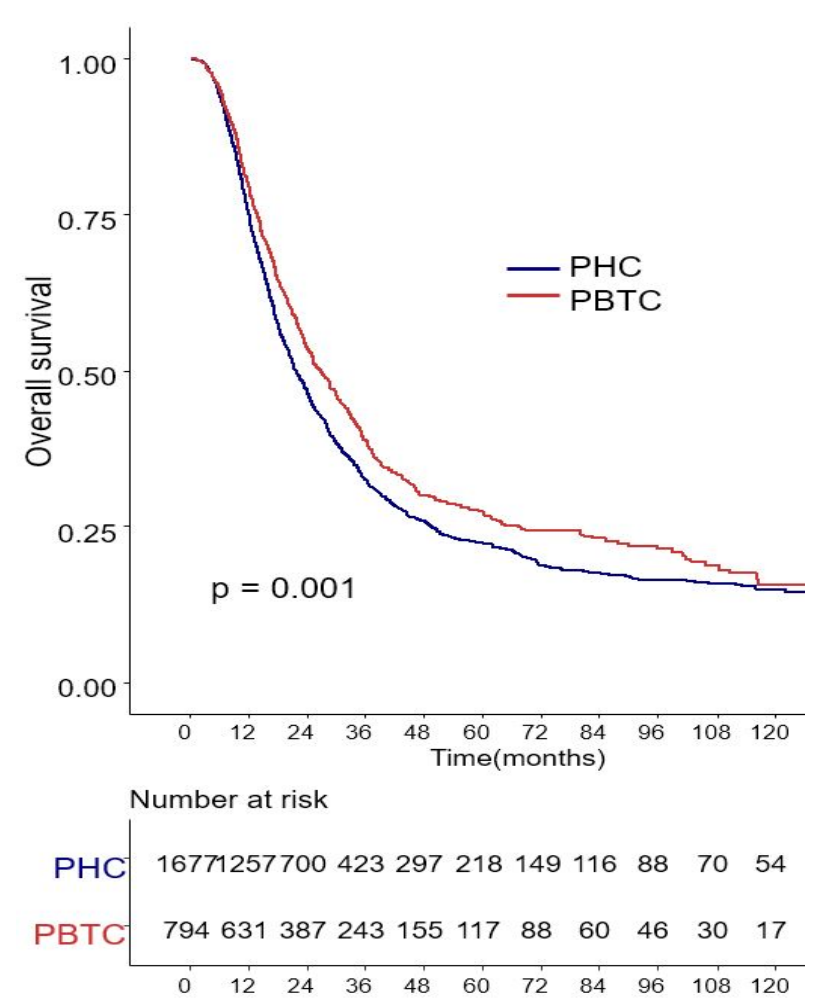

(a)

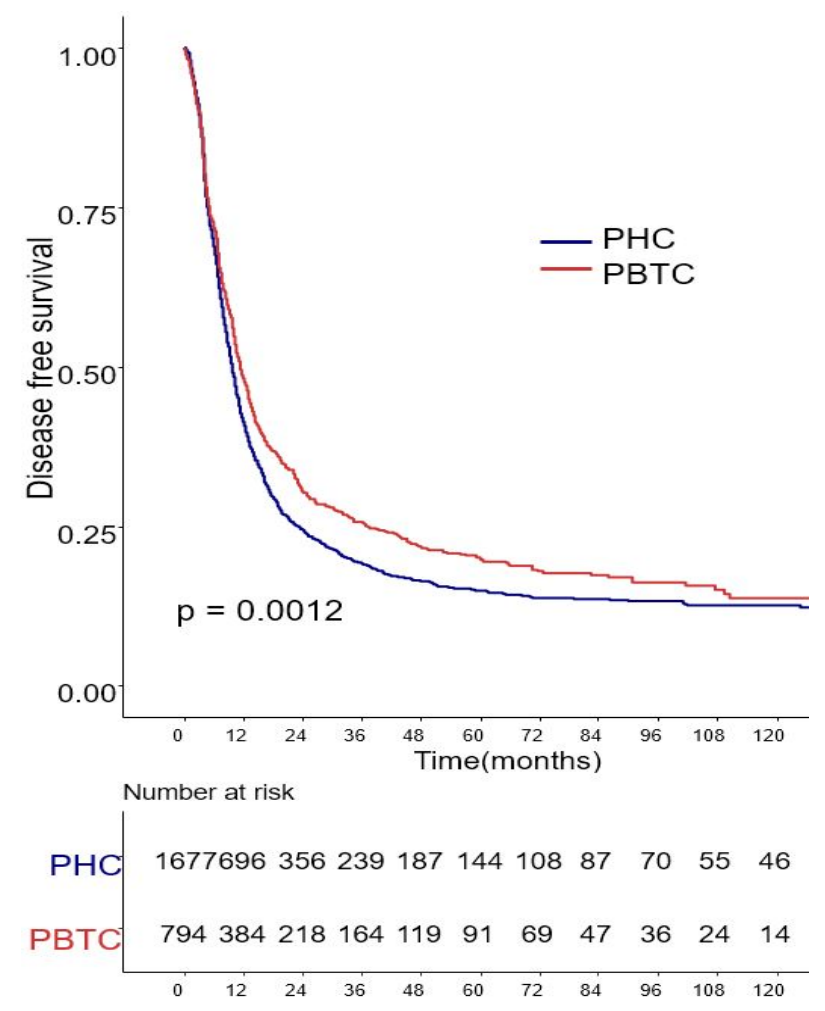

(b)

Figure 1. Kaplan-Meier survival curves of the cases in pancreatic head cancer (PHC) group $(n=1677)$ and pancreatic body/tail cancer (PBTC) group $(n=704)$. (a) The median overall survival (OS) and estimated 1-, 3-, and 5-year OS rates were 24.0 months and $75.0 \%, 25.2 \%$, and $13.0 \%$ in the PHC group, and 34.0 months and $79.5 \%, 30.6 \%$, and $14.7 \%$ in the PBTC group, respectively $(p=0.001)$. (b) The median disease-free survival (DFS) and estimated 1-, 3-, and 5-year DFS rates were 12.0 months and $41.5 \%, 14.3 \%$, and $8.6 \%$ in the PHC group, and 18.0 months and $48.4 \%, 20.7 \%$, and $11.5 \%$ in the PBTC group, respectively ( $p=0.0012$ ). 

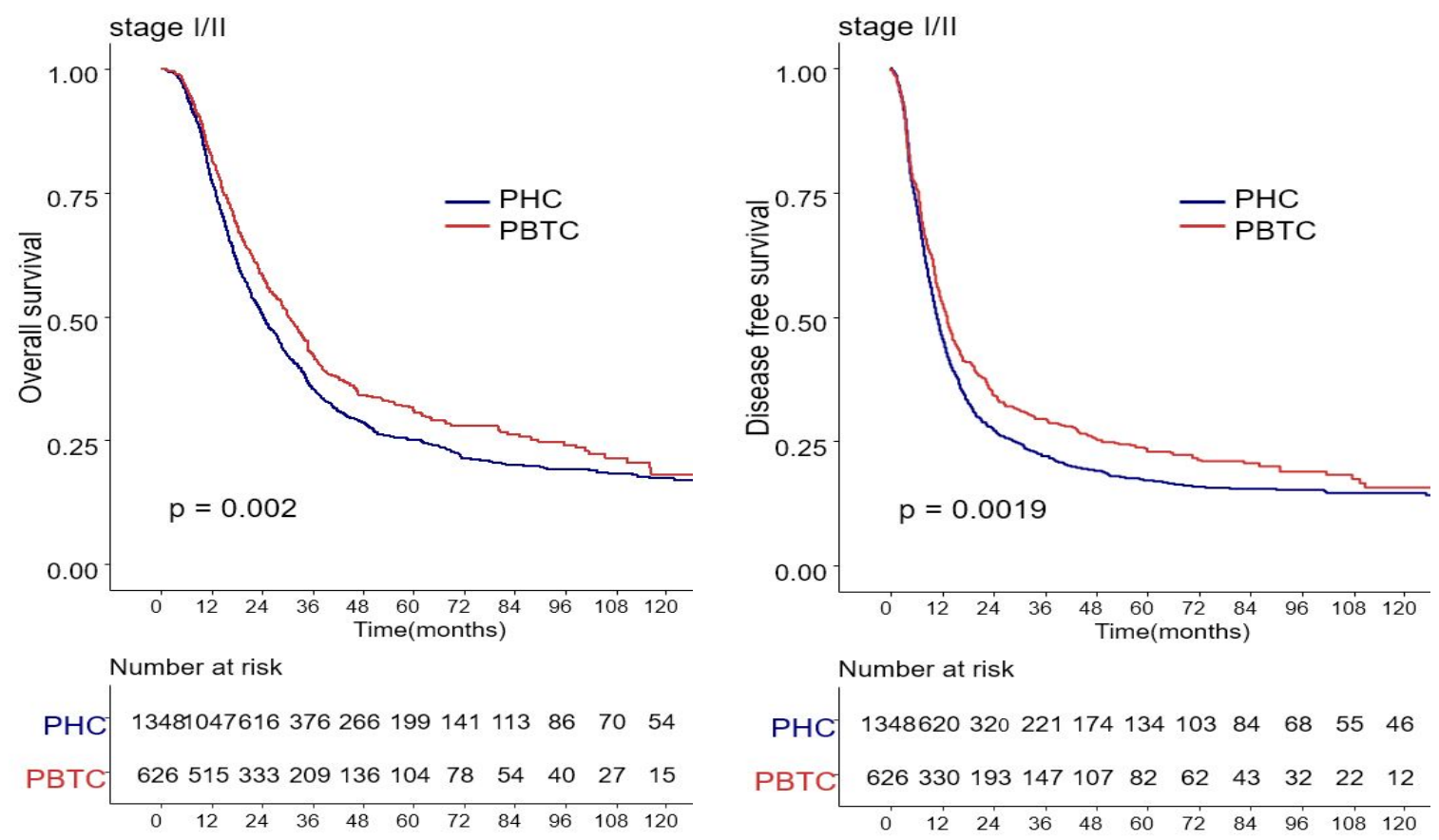

(a)

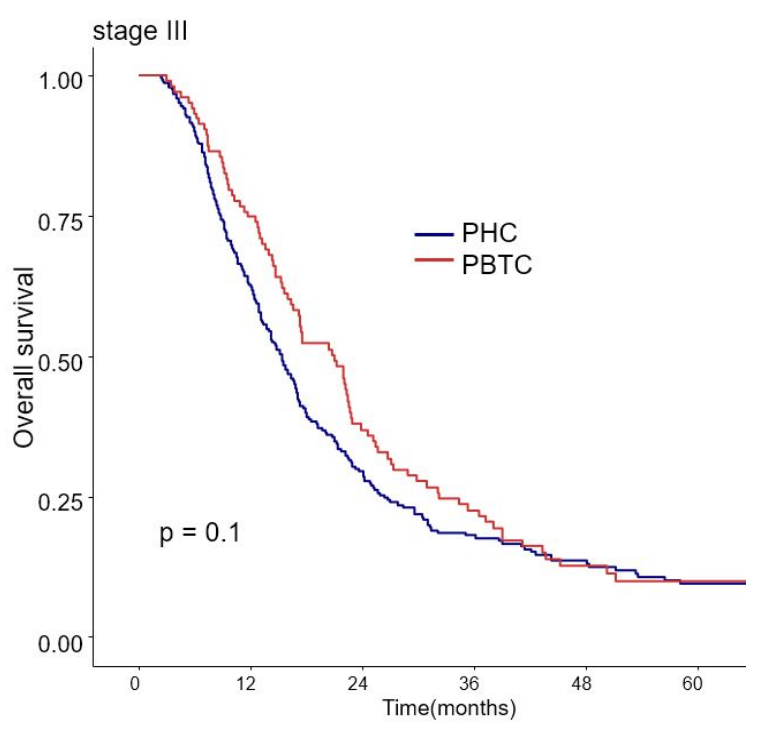

(b)
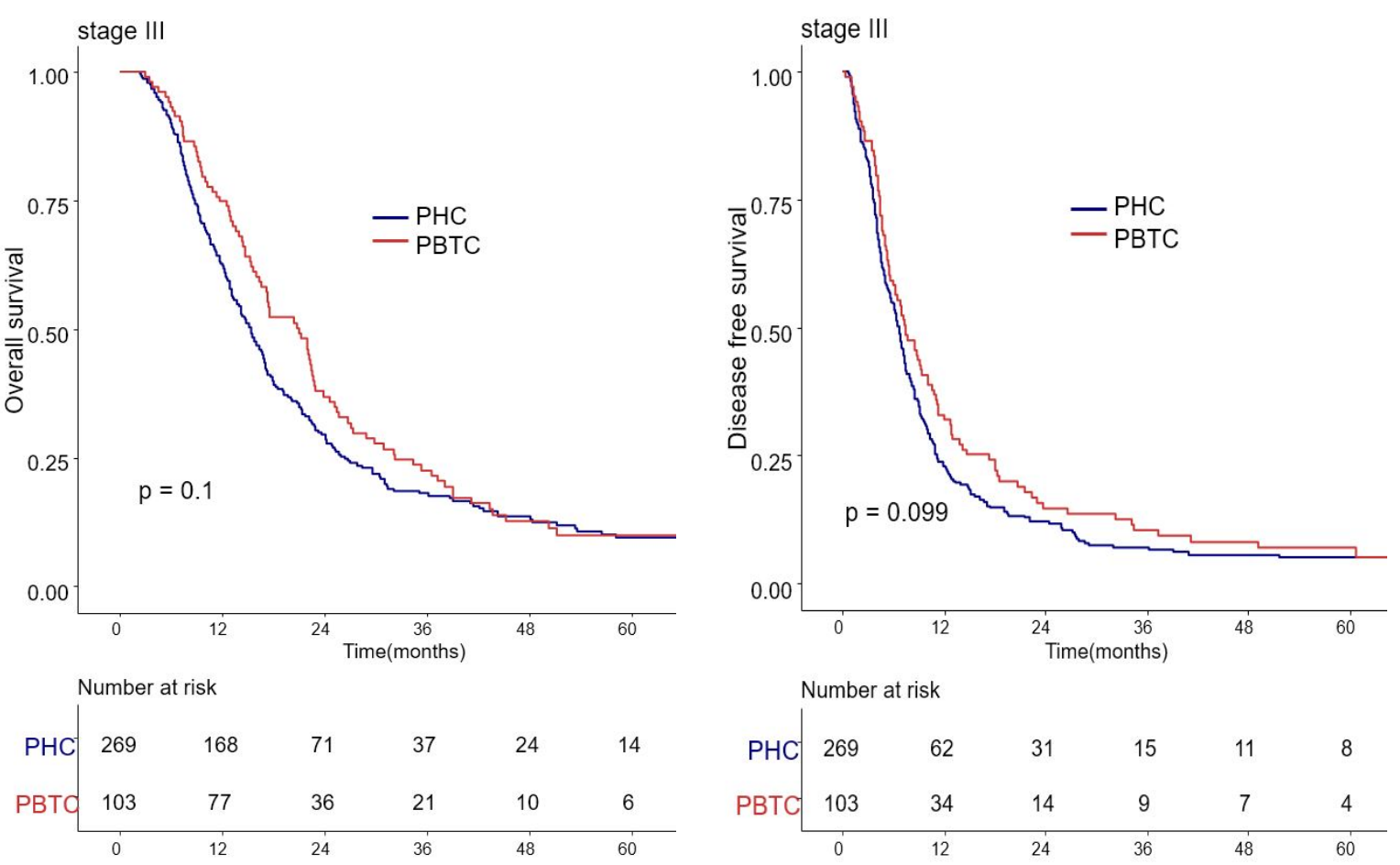

(c)

(d)

Figure 2. Kaplan-Meier survival curves of the cases in pancreatic head cancer (PHC) group $(n=1348)$ and pancreatic body/tail cancer (PBTC) group $(n=626)$, stratified according to cancer stage (I/II or III). (a) The median overall survival (OS) and estimated 1-, 3-, and 5-year OS rates for stage I/II were 24.0 months and $77.7 \%, 27.9 \%$, and $14.8 \%$ in the PHC group, and 30.0 months and $82.3 \%, 33.4 \%$, and $16.6 \%$ in the PBTC group, respectively $(p=0.002)$. (b) The median disease-free survival (DFS) and estimated 1-, 3-, and 5-year DFS rates for stage I/II were 10.0 months and 46.0\%, 16.4\%, and 9.9\% in the PHC group, and 13.0 months and 52.7\%, 23.5\%, and 13.1\% in the PBTC group, respectively $(p=0.0019)$. (c,d) However, no significant difference was found between PHC patients and those with stage III PDAC (overall survival: $p=0.1$, disease-free survival: $p=0.099)$. 

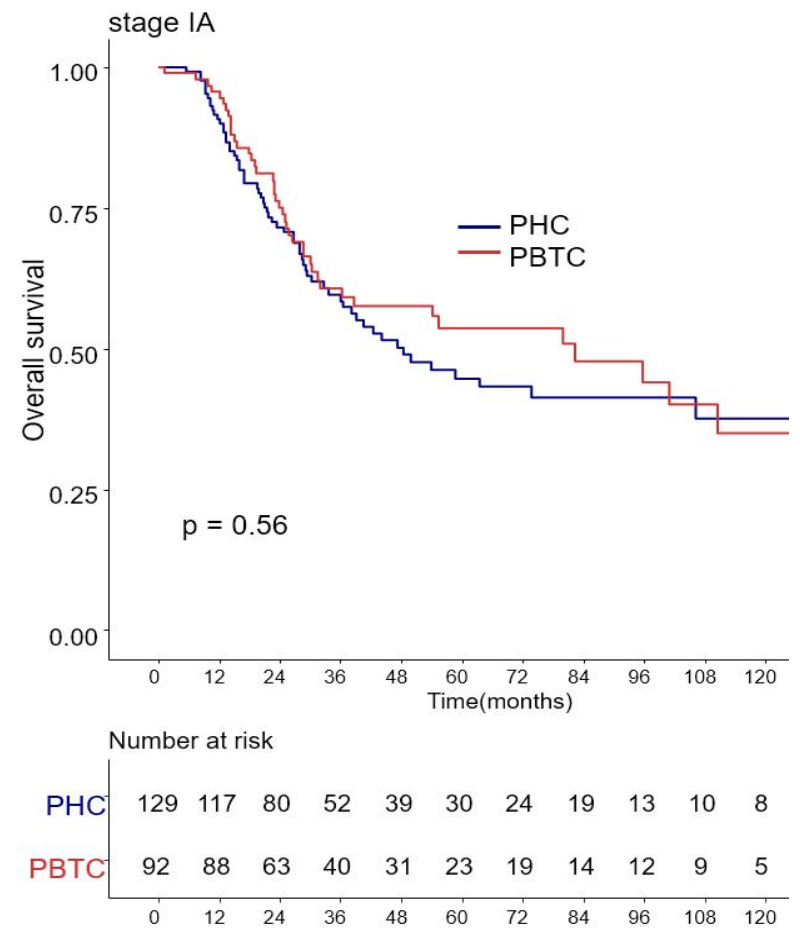

(a)

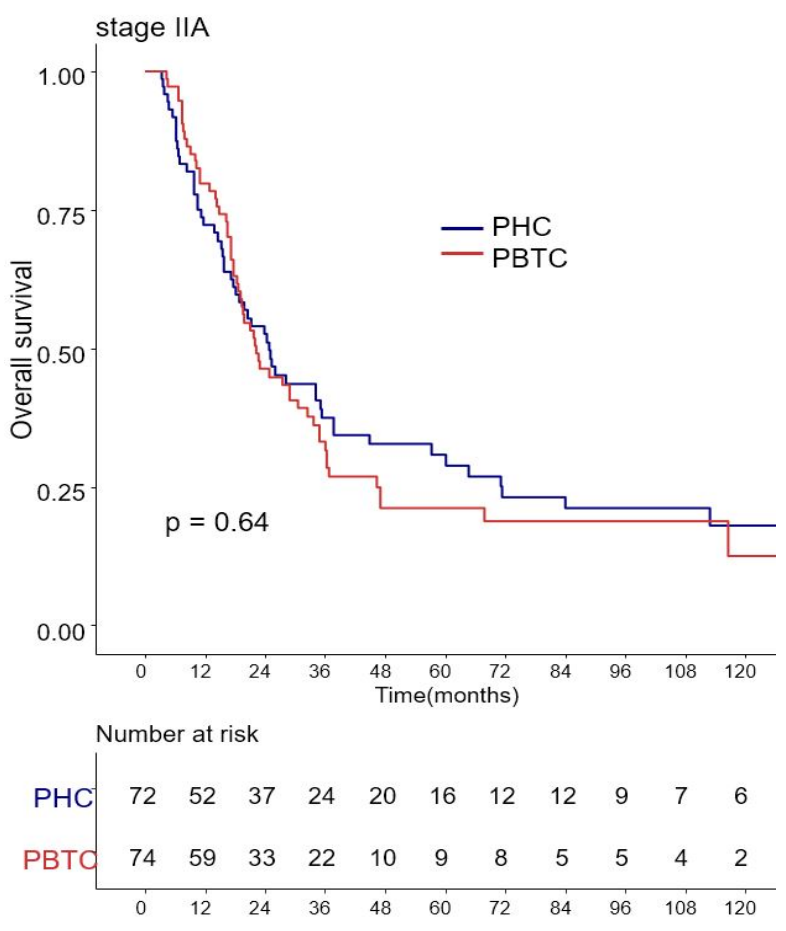

(c)
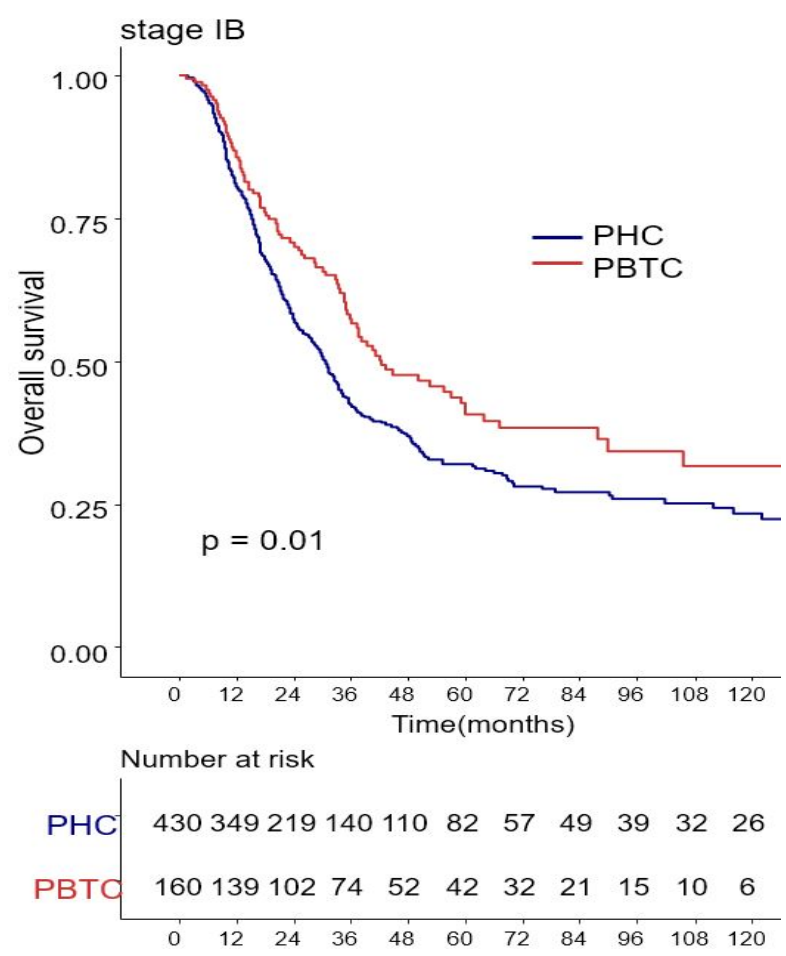

(b)
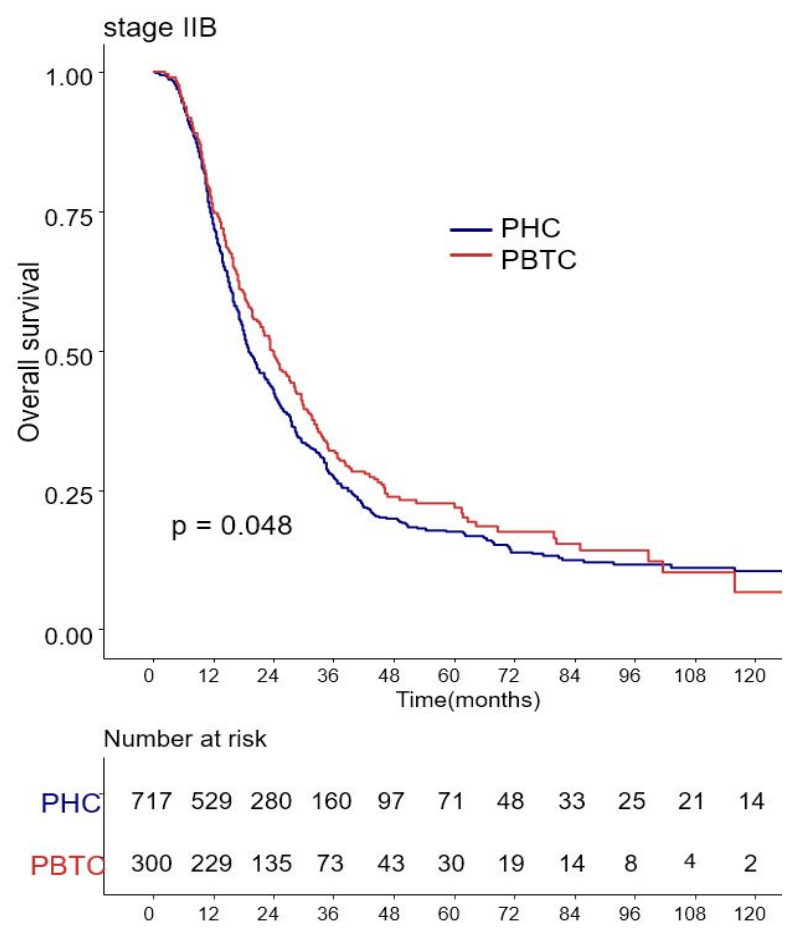

(d)

Figure 3. Kaplan-Meier survival curves of the cases in pancreatic head cancer (PHC) group and pancreatic body/tail cancer (PBTC) group, stratified according to the American Joint Committee on Cancer (AJCC 8th edition) Tumor-Node-Metastasis (TNM) staging system. (b) The survival rates were lower in PHC patients compared with PBTC patients in stage IB (30 months vs. 42 months, $p=0.011$ ) and (d) stage IIB (19 months vs. 23 months, $p=0.048)$. (a,c) No significant difference between the two groups was observed for stages IA and IIA. 
Table 3. Multivariate analysis for predictive factors of overall survival of pancreatic ductal adenocarcinoma patients.

\begin{tabular}{|c|c|c|c|c|c|}
\hline \multirow{3}{*}{ Location } & & \multicolumn{2}{|c|}{ Univariate } & \multicolumn{2}{|c|}{ Multivariate } \\
\hline & & \multicolumn{2}{|l|}{ HR (95\% CI) } & \multicolumn{2}{|l|}{ HR (95\% CI) } \\
\hline & Head & 1.000 & & 1.000 & \\
\hline \multirow{3}{*}{ Age (yrs) } & Body/tail & $0.846(0.766-0.935)$ & 0.001 & $1.041(0.923-1.173)$ & 0.513 \\
\hline & $<65$ & 1.000 & & & \\
\hline & $\geq 65$ & $1.086(0.989-1.192)$ & 0.084 & & \\
\hline \multirow[t]{2}{*}{ Sex } & Male & 1.000 & & & \\
\hline & Female & $1.126(1.025-1.237)$ & 0.014 & & \\
\hline \multirow[t]{2}{*}{$\operatorname{BMI}\left(\mathrm{kg} / \mathrm{m}^{2}\right)$} & $<25$ & 1.000 & & 1.000 & \\
\hline & $\geq 25$ & $0.799(0.712-0.896)$ & 0.001 & $0.862(0.767-0.968)$ & 0.012 \\
\hline \multirow[t]{2}{*}{ CA 19-9 } & Normal & 1.000 & & 1.000 & \\
\hline & Increased & $1.377(1.245-1.524)$ & 0.001 & $1.197(1.080-1.325)$ & 0.001 \\
\hline \multirow[t]{2}{*}{ CEA } & Normal & 1.000 & & & \\
\hline & Increased & $1.201(1.061-1.359)$ & 0.004 & & \\
\hline \multirow[t]{3}{*}{ mGPS } & 0 & 1.000 & & 1.000 & \\
\hline & 1 & $1.252(1.029-1.523)$ & 0.025 & $1.265(1.038-1.541)$ & 0.020 \\
\hline & 2 & $1.290(1.112-1.495)$ & 0.001 & $1.080(0.929-1.257)$ & 0.315 \\
\hline \multirow{2}{*}{ Period } & 2000-2009 & 1.000 & & & \\
\hline & 2010-2018 & $0.663(0.601-0.730)$ & 0.001 & & \\
\hline \multirow[t]{2}{*}{ Length of hospital stay } & $\leq 15$ & 1.000 & & 1.000 & \\
\hline & $>15$ & $1.457(1.328-1.598)$ & 0.001 & $1.266(1.144-1.401)$ & 0.001 \\
\hline \multirow[t]{3}{*}{ POPF } & No & 1.000 & & & \\
\hline & Grade A & $0.882(0.766-1.017)$ & 0.084 & & \\
\hline & Grade B or C & $0.976(0.793-1.203)$ & 0.823 & & \\
\hline \multirow[t]{3}{*}{ Complications } & No & 1.000 & & 1.000 & \\
\hline & Grade I-II & $1.179(1.065-1.307)$ & 0.002 & $1.134(1.020-1.262)$ & 0.021 \\
\hline & Grade III-IV & $1.115(0.929-1.337)$ & 0.243 & $1.041(0.863-1.256)$ & 0.672 \\
\hline \multirow[t]{3}{*}{ Adjuvant therapy } & No & 1.000 & & $\begin{array}{c}1.0 \pm 1(0.000-1.200) \\
1.000\end{array}$ & \\
\hline & CTx & $0.737(0.664-0.819)$ & 0.001 & $0.703(0.632-0.782)$ & 0.001 \\
\hline & CCRTx & $0.807(0.702-0.928)$ & 0.003 & $0.633(0.547-0.733)$ & 0.001 \\
\hline \multirow[t]{2}{*}{ Operation method } & Open & 1.000 & & 1.000 & \\
\hline & Lap/robot & $0.601(0.522-0.692)$ & 0.001 & $0.749(0.638-0.879)$ & 0.001 \\
\hline \multirow[t]{2}{*}{ Vein resection } & No & 1.000 & & 1.000 & \\
\hline & Yes & $1.557(1.407-1.724)$ & 0.001 & $1.222(1.096-1.363)$ & 0.001 \\
\hline Artery resection & No & 1.000 & & & \\
\hline & Yes & 1.587 (1.315-1.916) & 0.001 & & \\
\hline Combined resection & No & 1.000 & & & \\
\hline & Yes & $1.138(0.928-1.397)$ & 0.214 & & \\
\hline Tumor size (cm) & & $1.174(1.145-1.205)$ & 0.001 & $1.114(1.078-1.151)$ & 0.001 \\
\hline Differentiation & Well & 1.000 & & 1.000 & \\
\hline & Moderate & $1.689(1.430-1.994)$ & 0.001 & $1.457(1.236-1.718)$ & 0.001 \\
\hline & Poor & $2.858(2.342-3.486)$ & 0.001 & $2.393(1.965-2.915)$ & 0.001 \\
\hline T stage & $\mathrm{T} 1$ & 1.000 & & & \\
\hline & $\mathrm{T} 2$ & $1.640(1.416-1.901)$ & 0.001 & & \\
\hline & $\mathrm{T} 3$ & $2.257(1.907-2.670)$ & 0.001 & & \\
\hline & $\mathrm{T} 4$ & $3.052(2.112-4.409)$ & 0.001 & & \\
\hline N stage & No & 1.000 & & & \\
\hline & N1 & $1.681(1.514-1.866)$ & 0.001 & & \\
\hline & N2 & $2.346(2.050-2.684)$ & 0.001 & & \\
\hline M stage & M0 & 1.000 & & & \\
\hline & M1 & $1.961(1.591-2.417)$ & 0.001 & & \\
\hline TNM stage & IA & 1.000 & & 1.000 & \\
\hline & IB & $1.460(1.177-1.813)$ & 0.001 & $1.104(0.885-1.378)$ & 0.381 \\
\hline & IIA & $1.968(1.508-2.568)$ & 0.001 & $1.142(0.850-1.534)$ & 0.380 \\
\hline & IIB & $2.424(1.978-2.969)$ & 0.001 & $1.673(1.350-2.073)$ & 0.001 \\
\hline & III & $3.372(2.705-4.204)$ & 0.001 & $2.182(1.722-2.764)$ & 0.001 \\
\hline & IV & $4.024(3.043-5.321)$ & 0.001 & $2.530(1.880-3.406)$ & 0.001 \\
\hline
\end{tabular}


Table 3. Cont.

\begin{tabular}{|c|c|c|c|c|c|}
\hline & & \multicolumn{2}{|c|}{ Univariate } & \multicolumn{2}{|c|}{ Multivariate } \\
\hline & & HR (95\% CI) & & HR (95\% CI) & \\
\hline \multirow[t]{2}{*}{ LVI } & No & 1.000 & & 1.000 & \\
\hline & Yes & $1.521(1.386-1.670)$ & 0.001 & $1.266(1.147-1.398)$ & 0.001 \\
\hline \multirow[t]{2}{*}{ PNI } & No & 1.000 & & & \\
\hline & Yes & $1.468(1.295-1.664)$ & 0.001 & & \\
\hline \multirow[t]{2}{*}{$\mathrm{RM}$} & R0 & 1.00 & & 1.000 & \\
\hline & $\mathrm{R} 1$ & $1.393(1.256-1.546)$ & 0.001 & $1.194(1.066-1.337)$ & 0.002 \\
\hline
\end{tabular}

BMI, body mass index; CA, carbohydrate antigen; CEA, carcinoembryonic antigen; mGPS, modified Glasgow prognostic score; POPF, postoperative pancreatic fistula; CTx, chemotherapy; CCRTx, concurrent chemoradiation therapy; LVI, lymphovascular invasion; PNI, perineural invasion; RM, resection margin.

\section{Discussion}

In this study, the OS and DFS rates were worse in PHC patients compared with those in PBTC patients. Specifically, the OS and DFS rates in patients with stage I/II tumors, which are often diagnosed as relatively operable compared to stage III tumors, were worse in PHC patients compared with PBTC patients. When the stages were subdivided, the survival rate of PHC was consistently worse in stage IB and stage IIB patients. However, tumor location was not an independent prognostic factor. Elevated CA 19-9 levels, mGPS score 1, longer hospital stay (>15 days), complication Grade I-II, accompanying vein resection, larger tumor size, worse differentiation, higher TNM stage (stage IIB, III, IV), presence of LVI, and positive resection margin were associated with worse survival, and recent operation period, adjuvant therapy, and laparoscopic or robotic surgery were associated with better survival.

According to our findings, patients with PHC had worse survival compared with patients with PBTC. The worse prognosis of PHC could be attributed to the following reasons: First of all, the proportion of patients with LVI or PNI was higher among the PHC group. LVI or PNI, indicating aggressive tumor biology, often lead to poor prognosis [27]. Similar to our findings, several studies have reported higher $\mathrm{N}$ staging and higher prevalence of LVI and PNI among PHC patients [27-30]. This may imply different spread patterns and aggressiveness of cancer cells depending on primary tumor location. Another study reported poor differentiation of PHC even though the tumor size for PHC was smaller than that for PBTC [30]. Second, the different surgical procedures for PHC and PBTC may have contributed to the difference in overall survival rates. The radical antegrade modular pancreatosplenectomy (RAMPS) procedure, which is the standard operation method for PBTC, helps to achieve negative tangential margins for tumors [31]. Distal pancreatectomy, which does not require anastomosis after resection, is recognized as a safe alternative to open surgery for benign and low-malignancy tumors because laparoscopy was faster than pancreaticoduodenectomy [32,33]. For malignant tumors, no difference in postoperative complications or survival rates between PHC and PBTC have been reported [34]. Laparoscopy allows rapid post-operative recovery in PBTC patients and more efficient administration of adjuvant chemotherapy compared to open surgery. Therefore, the survival rate of these patients has improved significantly. Thirdly, PHC patients usually develop obstructive symptoms such as jaundice, which help in disease diagnosis. However, this may also delay surgery due to high bilirubin levels concomitant with poor general conditions [35]. Further, high bilirubin levels delay recovery after surgery, leading to a prolonged hospital stay. This may affect the prognosis of PHC patients as it can delay or prevent adjuvant chemotherapy after surgery. Furthermore, it is important to account for the role of micro-RNAs. Tumor location has been associated with miR-501-3p expression, which promotes carcinogenesis and recurrence of PDAC [36,37]. Low expression of miR-501-3p, associated with a lower risk of tumor recurrence, was more prevalent in PBTC patients compared with PHC patients [36,37]. 
AJCC TNM staging is the major prognostic factor used in clinical practice. In our data, the proportion of patients with high TNM staging was greater among the PHC group than the PBTC group. Therefore, we compared survival rates of PHC and PBTC for each stage based on the AJCC 8th edition. Stage III PDAC can be regarded as a relatively advanced cancer compared to stage I/II PDAC. Although there was no significant difference in the survival rate between the two groups in stage III PDAC, overall survival and DFS rates in stage I/II PDAC were lower in PHC patients compared to PBTC patients. When the patient group with stage I/II tumors was subdivided, PHC patients had a poorer survival rate than PBTC patients in stage IB and IIB. There was no significant difference in overall survival among patients with stage IA and IIA cancer. The 8th AJCC stage system defines stage IIB pancreatic cancer as a tumor with stage $\mathrm{N} 1$ regardless of stage $\mathrm{T}$. The low survival rate of patients with PHC in stage IIB can be explained by the results of our multivariate analysis. Patients with lymph node metastasis and R1 resection had a worse survival rate compared to others, and PHC patients had more lymph node metastasis [38]. The difference in survival rate among patients in stage IIB can also be attributed to the difference in surgical resection range. Since PHC has many important vascular structures around it and extends to the retroperitoneum adjacent to it, it is relatively difficult to perform a clear lymph node resection. Therefore, it is difficult to obtain complete R0 resection. However, it is relatively easier to obtain a safe R0 resection because the PBTC is relatively less constrained by the surrounding structure than the PHC $[39,40]$.

A worse survival rate for patients with stage IB PHC has also been observed in other studies. Ling et al. reported that PBTC had a lower expression of miR-501-3p compared to PHC. MiR-501-3p is known to cause the recurrence of tumors with aggressive cancer cell invasion. In the investigation of survival rate after pancreatic cancer resection, patients with metastatic disease are already excluded from surgical resection, so PBTC patients tend to have better survival than those with PHC. There was no significant difference in survival between the two groups in stage III cancer because this stage resembles a systemic disease, which includes tumor invasion to the celiac axis, superior mesenteric artery, and common hepatic artery. Other studies also did not report differences in the survival rates for this stage [21]. Wang et al. showed that tumor location of pancreatic cancer was not related to DFS in stage III pancreatic cancer patients [41]. The survival of PBTC patients in stage IB and IIB was better than the survival of PHC patients in the same stages. In fact, their survival was close to the survival of PHC patients in stages IA and IIA. Several studies have already validated TNM staging in the AJCC 8th edition; however, most of these were retrospective in design. Therefore, their results may need to be verified using the TNM staging system in a multicenter study.

Traditionally, it is known that PBTC has a worse prognosis than PHC. It is accepted that the primary reason for this is the delay in the onset of typical symptoms and final diagnosis. PHC can cause obstructive jaundice as the tumor progresses, whereas PBTC does not show symptoms until the tumor grows in size to an unresectable state. A large tumor size makes it less likely to be resected. It also increases the chances of systemic metastasis. This was demonstrated by studies that showed significantly lower survival rates for PBTCs in studies comparing 5-year survival rates regardless of resection potential $[4,9,13,16-19]$. However, based on the results of this study, when resection of PBTC is performed, the prognosis is better than that of PHC. Therefore, we suggest that more aggressive resection should be considered.

We confirmed that tumor location was not an independent prognostic factor. However, the findings for tumor location as a prognostic factor have varied in different studies. This suggests that there is a need to study pancreatic cancer at the bio-molecular, genetic level, to supplement clinical findings. Dreyer et al. showed that pancreatic cancer may have different molecular pathologies depending on tumor location and that PBTC genetic programs were associated with tumor invasion and poor antitumor immune responses [42]. Birnbaum et al. found differences in 334-gene expression signatures between PHC and PBTC [13]. Yin et al. analyzed differentially expressed genes and mutation signatures of 
PHC and PBTC [14]. It was argued that B cell and CD4+ T cell infiltration was higher in $\mathrm{PHC}$, and the MATH score, which is a method of assessing intratumoral heterogeneity, was higher in PBTC compared to PHC. These findings indicate prognostic and genetic differences between PHC and PBTC. Therefore, these tumors should be regarded as substantially different pathologies that require appropriate treatment plans.

There are several limitations in this study. First, this is a retrospective study, which does not establish causality. Second, our study samples were confined to a single tertiary center, possibly resulting in selection bias. However, since the sample size was very large and consecutive, this limitation was overcome even in the subgroup analysis. Third, lesions that extended to both head and body/tail regions were excluded from the beginning, which may have influenced the overall outcome. However, the number of such cases was small.

\section{Conclusions}

The overall survival rate of pancreatic cancer patients differs according to tumor location, and PHC and PBTC have different clinical, pathological, and biological characteristics. PHC patients had a lower OS and DFS than PBTC patients for resectable PDAC. However, tumor location was not an independent prognostic factor for resectable PDAC after adjusting for potential confounders.

Supplementary Materials: The following are available online at https: / www.mdpi.com/article / 10.3390/biomedicines9111706/s1, Table S1: Multivariate analysis for predictive factors of overall survival of pancreatic head cancer patients, Table S2: Multivariate analysis for predictive factors of overall survival of pancreatic body or tail cancer patients.

Author Contributions: Conceptualization, S.C.K.; methodology, M.K.S.; validation, W.L., D.W.H.; formal analysis, M.K.S.; resources, E.J., K.B.S., J.H.L.; data curation, Y.P., B.J.K.; writing—original draft preparation, M.K.S.; writing—review and editing, M.K.S., S.C.K.; supervision, S.C.K.; All authors have read and agreed to the published version of the manuscript.

Funding: This research received no external funding.

Institutional Review Board Statement: The study was conducted according to the guidelines of the Declaration of Helsinki and was approved by the institutional review board of the Asan Medical Center (approval number, 2021-1231 and approval date: 15 August 2021).

Informed Consent Statement: Not applicable.

Data Availability Statement: The data presented in this study are available on request from the corresponding author. The data are not publicly available due to private information of patients.

Conflicts of Interest: The authors declare no conflict of interest.

\section{References}

1. Pourshams, A.; Sepanlou, S.G.; Ikuta, K.S.; Bisignano, C.; Safiri, S.; Roshandel, G.; Sharif, M.; Khatibian, M.; Fitzmaurice, C.; Nixon, M.R.; et al. The global, regional, and national burden of pancreatic cancer and its attributable risk factors in 195 countries and territories, 1990-2017: A systematic analysis for the Global Burden of Disease Study 2017. Lancet. Gastroenterol. Hepatol. 2019, 4, 934-947. [CrossRef]

2. Rawla, P.; Sunkara, T.; Gaduputi, V. Epidemiology of Pancreatic Cancer: Global Trends, Etiology and Risk Factors. World J. Oncol. 2019, 10, 10-27. [CrossRef]

3. McGuigan, A.; Kelly, P.; Turkington, R.C.; Jones, C.; Coleman, H.G.; McCain, R.S. Pancreatic cancer: A review of clinical diagnosis, epidemiology, treatment and outcomes. World J. Gastroenterol. 2018, 24, 4846-4861. [CrossRef]

4. Artinyan, A.; Soriano, P.A.; Prendergast, C.; Low, T.; Ellenhorn, J.D.; Kim, J. The anatomic location of pancreatic cancer is a prognostic factor for survival. HPB Off. J. Int. Hepato Pancreato Biliary Assoc. 2008, 10, 371-376. [CrossRef] [PubMed]

5. van Erning, F.N.; Mackay, T.M.; van der Geest, L.G.M.; Groot Koerkamp, B.; van Laarhoven, H.W.M.; Bonsing, B.A.; Wilmink, J.W.; van Santvoort, H.C.; de Vos-Geelen, J.; van Eijck, C.H.J.; et al. Association of the location of pancreatic ductal adenocarcinoma (head, body, tail) with tumor stage, treatment, and survival: A population-based analysis. Acta Oncol. 2018, 57, 1655-1662. [CrossRef] [PubMed]

6. Tomasello, G.; Ghidini, M.; Costanzo, A.; Ghidini, A.; Russo, A.; Barni, S.; Passalacqua, R.; Petrelli, F. Outcome of head compared to body and tail pancreatic cancer: A systematic review and meta-analysis of 93 studies. J. Gastrointest. Oncol. 2019, 10, 259-269. [CrossRef] [PubMed] 
7. Ruess, D.A.; Makowiec, F.; Chikhladze, S.; Sick, O.; Riediger, H.; Hopt, U.T.; Wittel, U.A. The prognostic influence of intrapancreatic tumor location on survival after resection of pancreatic ductal adenocarcinoma. BMC Surg. 2015, 15, 123. [CrossRef] [PubMed]

8. Meng, Z.; Cao, M.; Zhang, Y.; Liu, Z.; Wu, S.; Wu, H. Tumor location as an indicator of survival in T1 resectable pancreatic ductal adenocarcinoma: A propensity score-matched analysis. BMC Gastroenterol. 2019, 19, 59. [CrossRef]

9. Lau, M.K.; Davila, J.A.; Shaib, Y.H. Incidence and survival of pancreatic head and body and tail cancers: A population-based study in the United States. Pancreas 2010, 39, 458-462. [CrossRef]

10. Brennan, M.F.; Moccia, R.D.; Klimstra, D. Management of adenocarcinoma of the body and tail of the pancreas. Ann. Surg. 1996, 223, 506-511; discussion 511-512. [CrossRef]

11. Sheng, W.; Dong, M.; Wang, G.; Shi, X.; Gao, W.; Wang, K.; Song, H.; Shi, G.; Tan, X. The diversity between curatively resected pancreatic head and body-tail cancers based on the 8th edition of AJCC staging system: A multicenter cohort study. BMC Cancer 2019, 19, 981. [CrossRef] [PubMed]

12. Malleo, G.; Maggino, L.; Ferrone, C.R.; Marchegiani, G.; Luchini, C.; Mino-Kenudson, M.; Paiella, S.; Qadan, M.; Scarpa, A.; Lillemoe, K.D.; et al. Does Site Matter? Impact of Tumor Location on Pathologic Characteristics, Recurrence, and Survival of Resected Pancreatic Ductal Adenocarcinoma. Ann. Surg. Oncol. 2020, 27, 3898-3912. [CrossRef] [PubMed]

13. Birnbaum, D.J.; Bertucci, F.; Finetti, P.; Birnbaum, D.; Mamessier, E. Head and Body/Tail Pancreatic Carcinomas Are Not the Same Tumors. Cancers 2019, 11, 497. [CrossRef]

14. Yin, L.; Xiao, L.; Gao, Y.; Wang, G.; Gao, H.; Peng, Y.; Zhu, X.; Wei, J.; Miao, Y.; Jiang, K.; et al. Comparative bioinformatical analysis of pancreatic head cancer and pancreatic body/tail cancer. Med. Oncol. 2020, 37, 46. [CrossRef] [PubMed]

15. Yamamoto, J.; Saiura, A.; Koga, R.; Seki, M.; Katori, M.; Kato, Y.; Sakamoto, Y.; Kokudo, N.; Yamaguchi, T. Improved survival of left-sided pancreas cancer after surgery. Jpn. J. Clin. Oncol. 2010, 40, 530-536. [CrossRef]

16. Watanabe, I.; Sasaki, S.; Konishi, M.; Nakagohri, T.; Inoue, K.; Oda, T.; Kinoshita, T. Onset symptoms and tumor locations as prognostic factors of pancreatic cancer. Pancreas 2004, 28, 160-165. [CrossRef]

17. Sohn, T.A.; Yeo, C.J.; Cameron, J.L.; Koniaris, L.; Kaushal, S.; Abrams, R.A.; Sauter, P.K.; Coleman, J.; Hruban, R.H.; Lillemoe, K.D. Resected adenocarcinoma of the pancreas-616 patients: Results, outcomes, and prognostic indicators. J. Gastrointest. Surg. 2000, 4, 567-579. [CrossRef]

18. Wade, T.P.; Virgo, K.S.; Johnson, F.E. Distal pancreatectomy for cancer: Results in U.S. Department of Veterans Affairs hospitals, 1987-1991. Pancreas 1995, 11, 341-344. [CrossRef]

19. Toomey, P.; Hernandez, J.; Golkar, F.; Ross, S.; Luberice, K.; Rosemurgy, A. Pancreatic adenocarcinoma: Complete tumor extirpation improves survival benefit despite larger tumors for patients who undergo distal pancreatectomy and splenectomy. J. Gastrointest. Surg. 2012, 16, 376-381. [CrossRef]

20. Winer, L.K.; Dhar, V.K.; Wima, K.; Morris, M.C.; Lee, T.C.; Shah, S.A.; Ahmad, S.A.; Patel, S.H. The Impact of Tumor Location on Resection and Survival for Pancreatic Ductal Adenocarcinoma. J. Surg. Res. 2019, 239, 60-66. [CrossRef]

21. Zheng, Z.; Wang, M.; Tan, C.; Chen, Y.; Ping, J.; Wang, R.; Liu, X. Disparities in survival by stage after surgery between pancreatic head and body/tail in patients with nonmetastatic pancreatic cancer. PLoS ONE 2019, 14, e0226726. [CrossRef]

22. Imaoka, H.; Mizuno, N.; Hara, K.; Hijioka, S.; Tajika, M.; Tanaka, T.; Ishihara, M.; Yogi, T.; Tsutsumi, H.; Fujiyoshi, T.; et al. Evaluation of Modified Glasgow Prognostic Score for Pancreatic Cancer: A Retrospective Cohort Study. Pancreas 2016, 45, $211-217$. [CrossRef]

23. Distler, M.; Pilarsky, E.; Kersting, S.; Grützmann, R. Preoperative CEA and CA 19-9 are prognostic markers for survival after curative resection for ductal adenocarcinoma of the pancreas-A retrospective tumor marker prognostic study. Int. J. Surg. 2013, 11, 1067-1072. [CrossRef] [PubMed]

24. Pulvirenti, A.; Ramera, M.; Bassi, C. Modifications in the International Study Group for Pancreatic Surgery (ISGPS) definition of postoperative pancreatic fistula. Transl. Gastroenterol. Hepatol. 2017, 2, 107. [CrossRef] [PubMed]

25. Téoule, P.; Bartel, F.; Birgin, E.; Rückert, F.; Wilhelm, T.J. The Clavien-Dindo Classification in Pancreatic Surgery: A Clinical and Economic Validation. J. Investig. Surg. Off. J. Acad. Surg. Res. 2019, 32, 314-320. [CrossRef]

26. Chun, Y.S.; Pawlik, T.M.; Vauthey, J.N. 8th Edition of the AJCC Cancer Staging Manual: Pancreas and Hepatobiliary Cancers. Ann. Surg. Oncol. 2018, 25, 845-847. [CrossRef]

27. Chatterjee, D.; Katz, M.H.; Rashid, A.; Wang, H.; Iuga, A.C.; Varadhachary, G.R.; Wolff, R.A.; Lee, J.E.; Pisters, P.W.; Crane, C.H.; et al. Perineural and intraneural invasion in posttherapy pancreaticoduodenectomy specimens predicts poor prognosis in patients with pancreatic ductal adenocarcinoma. Am. J. Surg. Pathol. 2012, 36, 409-417. [CrossRef]

28. Fernández-Cruz, L.; Johnson, C.; Dervenis, C. Locoregional dissemination and extended lymphadenectomy in pancreatic cancer. Dig. Surg. 1999, 16, 313-319. [CrossRef] [PubMed]

29. Malleo, G.; Maggino, L.; Ferrone, C.R.; Marchegiani, G.; Mino-Kenudson, M.; Capelli, P.; Rusev, B.; Lillemoe, K.D.; Bassi, C.; Fernàndez-Del Castillo, C.; et al. Number of Examined Lymph Nodes and Nodal Status Assessment in Distal Pancreatectomy for Body/Tail Ductal Adenocarcinoma. Ann. Surg. 2019, 270, 1138-1146. [CrossRef]

30. Moon, H.J.; An, J.Y.; Heo, J.S.; Choi, S.H.; Joh, J.W.; Kim, Y.I. Predicting survival after surgical resection for pancreatic ductal adenocarcinoma. Pancreas 2006, 32, 37-43. [CrossRef] 
31. Sivasanker, M.; Desouza, A.; Bhandare, M.; Chaudhari, V.; Goel, M.; Shrikhande, S.V. Radical antegrade modular pancreatosplenectomy for all pancreatic body and tail tumors: Rationale and results. Langenbeck's Arch. Surg. 2019, 404, 183-190. [CrossRef]

32. Mehrabi, A.; Hafezi, M.; Arvin, J.; Esmaeilzadeh, M.; Garoussi, C.; Emami, G.; Kössler-Ebs, J.; Müller-Stich, B.P.; Büchler, M.W.; Hackert, T.; et al. A systematic review and meta-analysis of laparoscopic versus open distal pancreatectomy for benign and malignant lesions of the pancreas: It's time to randomize. Surgery 2015, 157, 45-55. [CrossRef] [PubMed]

33. Ricci, C.; Casadei, R.; Taffurelli, G.; Pacilio, C.A.; Minni, F. Laparoscopic distal pancreatectomy: Many meta-analyses, few certainties. Updates Surg. 2016, 68, 225-234. [CrossRef] [PubMed]

34. de Rooij, T.; van Hilst, J.; Busch, O.R.; Dijkgraaf, M.G.; Kooby, D.A.; Abu Hilal, M.; Besselink, M.G. Laparoscopic Distal Pancreatectomy for Pancreatic Ductal Adenocarcinoma: Time for a Randomized Controlled Trial? Results of an All-inclusive National Observational Study. Ann. Surg. 2017, 266, e84. [CrossRef]

35. Moole, H.; Bechtold, M.; Puli, S.R. Efficacy of preoperative biliary drainage in malignant obstructive jaundice: A meta-analysis and systematic review. World J. Surg. Oncol. 2016, 14, 182. [CrossRef] [PubMed]

36. Li, A.; Yu, J.; Kim, H.; Wolfgang, C.L.; Canto, M.I.; Hruban, R.H.; Goggins, M. MicroRNA array analysis finds elevated serum miR-1290 accurately distinguishes patients with low-stage pancreatic cancer from healthy and disease controls. Clin. Cancer Res. Off. J. Am. Assoc. Cancer Res. 2013, 19, 3600-3610. [CrossRef]

37. Ling, Q.; Xu, X.; Ye, P.; Xie, H.; Gao, F.; Hu, Q.; Liu, Z.; Wei, X.; Röder, C.; Trauzold, A.; et al. The prognostic relevance of primary tumor location in patients undergoing resection for pancreatic ductal adenocarcinoma. Oncotarget 2017, 8, 15159-15167. [CrossRef] [PubMed]

38. Morales-Oyarvide, V.; Rubinson, D.A.; Dunne, R.F.; Kozak, M.M.; Bui, J.L.; Yuan, C.; Qian, Z.R.; Babic, A.; Da Silva, A.; Nowak, J.A.; et al. Lymph node metastases in resected pancreatic ductal adenocarcinoma: Predictors of disease recurrence and survival. Br. J. Cancer 2017, 117, 1874-1882. [CrossRef]

39. Comito, T.; Cozzi, L.; Zerbi, A.; Franzese, C.; Clerici, E.; Tozzi, A.; Iftode, C.; Navarria, P.; D'Agostino, G.; Fogliata, A.; et al. Clinical results of stereotactic body radiotherapy (SBRT) in the treatment of isolated local recurrence of pancreatic cancer after R0 surgery: A retrospective study. Eur. J. Surg. Oncol. 2017, 43, 735-742. [CrossRef]

40. Groot, V.P.; van Santvoort, H.C.; Rombouts, S.J.; Hagendoorn, J.; Borel Rinkes, I.H.; van Vulpen, M.; Herman, J.M.; Wolfgang, C.L.; Besselink, M.G.; Molenaar, I.Q. Systematic review on the treatment of isolated local recurrence of pancreatic cancer after surgery; re-resection, chemoradiotherapy and SBRT. HPB Off. J. Int. Hepato Pancreato Biliary Assoc. 2017, 19, 83-92. [CrossRef]

41. Wang, L.; Cheng, C.S.; Chen, L.; Chen, Z. Benefit from the inclusion of surgery in the treatment of patients with stage III pancreatic cancer: A propensity-adjusted, population-based SEER analysis. Cancer Manag. Res. 2018, 10, 1907-1918. [CrossRef] [PubMed]

42. Dreyer, S.B.; Jamieson, N.B.; Upstill-Goddard, R.; Bailey, P.J.; McKay, C.J.; Biankin, A.V.; Chang, D.K. Defining the molecular pathology of pancreatic body and tail adenocarcinoma. Br. J. Surg. 2018, 105, e183-e191. [CrossRef] [PubMed] 